\title{
HOW THE TRIANGLE OF BOLOGNA QUALITY ASSURANCE, A NATIONAL LEGAL FRAMEWORK AND INTERNAL QUALITY ENHANCEMENT SUPPORTS INSTITUTIONAL IMPROVEMENT
}

\section{Kareva Veronika}

South East European University, v.kareva@seeu.edu.mk;

\section{Dika Zamir}

South East European University, z.dika@seeu.edu.mk;

Henshaw Heather, South East European University, h.henshaw@seeu.edu.mk

Memedi Xhevair

South east European University, xh.memedi@seeu.edu.mk

DOI: 10.1515/seeur-2017-0008

\section{Abstract}

The Republic of Macedonia (RM) has been a part of the Bologna process since 2003. The Ministry of Education, law and policy makers and higher education institutions have actively engaged with its main concepts. In parallel with this, since the adoption of the law on higher education in 2008 and the reform of the Accreditation and Evaluation Board, there have been numerous changes and amendments culminating in the fast-tracked adoption of a new law at the beginning of 2015. Some of its solutions created a huge debate among the academic community, other intellectuals and students themselves, resulting in the postponement of that law and a kind of legal vacuum. In such turbulent circumstances, individual higher education institutions had to consider how and to what extent to adopt and develop relevant standards and guidelines, 
comply with the legal framework and promote good practice. The aim of this paper is to present how these three aspects, Bologna standards and guidelines for Quality Assurance (QA), a national legal framework and an institutional approach are being reflected, merged and implemented at a relatively young higher education institution. It questions the impact of these three elements on each other and how one institution's drive for improvement is affected. This is done through a qualitative analysis of the three-fold perspectives. The conclusions and recommendations are expected to be of use to policy makers in the country and region as they evaluate how international trends and good practice fit into the socio-economic and political conditions of RM and similar countries. At the same time, it can demonstrate how far institutional quality assurance and progress can be implemented and recognized in the country itself and by some international stakeholders. It can also prove that the South East European University (SEEU) is a national leader in this field as RM has no functioning QA evaluation system, while SEEU has managed to create a well structured and operating one, based on international and institutional experiences.

Key words: quality assurance, triangle, institutional progress

\section{Introduction}

The Republic of Macedonia (RM) has been a full member of the Bologna process since 2003. The Ministry of Education, law and policy makers and higher education institutions have actively engaged with its main concepts. In parallel with this, since the adoption of a major new law on higher education in 2008 and the reform of the Evaluation and Accreditation Board, there have been numerous changes and amendments culminating in the fast-tracked adoption of a new law at the beginning of 2015. Amongst other things, this revised the previously adopted three year undergraduate study cycle and returned to a four year model and gave new powers to the Accreditation and Evaluation Board, which had not yet developed its previous remit effectively. It also introduced compulsory national external testing comprising of five multiple choice questions per course with the external test determining student progression and graduation. This created for the first time a huge debate with public protests by the academic community, other intellectuals and students themselves, resulting in the postponement of that law. The government was forced to announce a process of revision of the latest amendments including consultation with all involved parties, especially students and university professors. The nature of this consultative process and 
legal revisions are up to now not clearly defined. In the meantime, in June 2015, the Parliament adopted another set of changes to the existing Law on Higher Education from 2008, mainly related to the postponement of some requirements already defined in the older version.

Therefore, the context in which higher education institutions in the Republic of Macedonian function, including South East European University (SEEU), is characterized by uncertainties about the legal solutions; general dissatisfaction with repeated, poorly considered reforms; the effects of more general policies such as massification, with places for $90 \%$ and more of school leavers or the dispersion of provision into many centers; the inconsistent functioning of the Accreditation and Evaluation Board; political interference; and the need for more active student involvement. In such circumstances, individual higher education institutions had to consider how and to what extent to adopt and develop relevant standards and guidelines, comply with the legal framework and promote good practice, including relevant international trends.

The aim of this paper is to present how these three aspects - Bologna standards and guidelines for Quality Assurance (QA), a national legal framework and an institutional approach are being reflected, merged and implemented at a relatively young higher education institution. A qualitative analysis of the three different viewpoints mentioned previously is presented in order to review them and bring some conclusions and recommendations that may be useful for national policy makers, SEEU and other higher education institutions in the country or regionally.

\section{Overview of $Q A$ from the Bologna viewpoint}

Encouraging engagement in quality assurance processes in higher education was one of the purposes of the Bologna Declaration (1999). The intention was to develop comparable criteria and methodologies and this resulted in the adoption of the Standards and Guidelines (ESG) for Quality Assurance in the European Higher Education Area (EHEA) in 2005, drafted by the European Association for Quality Assurance in Higher Education (ENQA). The Bologna Communiqué from the Ministerial meeting in Yerevan in 2015 re-affirms key common goals and commitment towards quality higher education based on "public responsibility for higher education, academic freedom, institutional autonomy, and commitment to integrity". These crucial areas include internationalization and mobility of staff and students, focus on research, study programs tailored to fit the labor market and increase employability in terms of equipping students with the appropriate knowledge, 
skills and competences. It also included efforts to enable universities to "promote intercultural understanding, critical thinking, political and religious tolerance, gender equality, and democratic and civic values, in order to strengthen European and global citizenship and lay the foundations for inclusive societies"

In particular, the Communiqué stresses the importance of continuing to innovate and improve in the area of learning and teaching:

"Enhancing the quality and relevance of learning and teaching is the main mission of the EHEA. We will encourage and support higher education institutions and staff in promoting pedagogical innovation in student centered learning environments and in fully exploiting the potential benefits of digital technologies for learning and teaching...It is essential to recognize and support quality teaching, and to provide opportunities for enhancing academics' teaching competences. Moreover, we will actively involve students, as full members of the academic community, as well as other stakeholders, in curriculum design and in quality assurance".

According to the EUA Trends Report from 2015 (the last report being in 2010), the positive developments can be summarized as follows:

- predominance of internationalization in the development and improvement of learning and teaching suggesting that the quality of learning and teaching has increased thanks to student and staff mobility;

- insistence on the ICT developments expected to contribute to more flexible access to learning tools and the effectiveness of classroom time;

- "a growing recognition of the importance of teaching", as reported by nearly $60 \%$ of the institutions (p.93);

- quality of the teaching supported by quality assurance processes, including student evaluations (93\%) and by the work of academic development units $(60 \%)$.

It should be noted that these trends are not consistently implemented or fully developed everywhere in Europe. For instance, with regard to QA, "the existence of internal quality processes does not necessarily signal the development of a genuine quality culture" (p. 94) and national socio-economic and political factors also influence the development of QA to a great extent. In addition, some elements have met with a mixed reception, so as the Multirank initiative (EUA Case Studies, 2015). The Republic of Macedonia has adopted on paper almost all these initiatives and SEEU has made efforts to implement important elements such as ECTS and to use other trends to share planning and guide practice. 


\section{The Legal context in $R M$ with reference to $Q A$}

The Law on Higher Education of RM provides a quite specific, highly detailed and regulated legal framework for QA and higher education, with little room for autonomy or broader development of practice. As a concept, it is defined in article 2 point 10 as "an assessment of the quality of higher education covering numerous explicit procedures for assessment of the quality of the higher education institutions, academic staff, and their study programs in accordance with the accepted procedures and standards and the guidelines (instructions) for quality assurance adopted by the European higher education quality assurance institutions and other organizations and associations having the role to establish and apply the European standards and guidelines for quality assurance in the European higher education area" (Zakon za visoko obrazovanie na RM, p. 2).

It is further regulated in part VI - Assurance and Assessment of the Quality of Higher Education, article 68, which determines the components of the system for quality assurance and assessment as follows:

- recognition and confirmation of the institution and the study programs through accreditation;

- estimation of the quality of performance, the management of the institution, financing, academic and other activities through a system of evaluation;

- other activities and mechanisms determined by the law through which quality is developed and sustained.

The Law also states that, "the results of the evaluation and the quality of the higher education are explained in reports that are available to the public", (p.35).There is also a legal requirement for a two year, national Ranking exercise, which has been conducted twice so far. This has been accepted but deemed to be somewhat partial in its criteria and potentially open to political influence.

The articles that follow $(69,70,71$ and 72$)$ refer to the Accreditation Board, respectively - its structure and election, the competencies, its organization and work. This part of the Law is in line with the Standards and Guidelines for Quality Assurance in the European Higher Education Area.

Articles 73, 74, 75, 76 and 77 from the Law refer to the evaluation of the institutions of higher education, including the external evaluation and the Evaluation Agency, its competencies, organization and work, while article 77 refers to the self-evaluation, which is a way of internal evaluation. The 
law and guidance documentation for the responsibilities and function of the Accreditation and Evaluation Board are clearly defined. This body has functioned with regard to the accreditation of study programs. However, it has not engaged in evaluation activities, except to ask for institutional selfevaluation reports to be published. It acts as a state organ represented by a President appointed by the Government; and has not carried out not any institutional reviews or any other notable activity identified or related to its brief. The latest, now postponed higher education amendments, would have given this body even more powers.

Therefore, it can be seen that whereas the Law does provide legal solutions for the national QA system and the Accreditation and Evaluation Board does have a positive remit, these are somewhat notional and it remains to the institutions of higher education to determine and operationalize the development of Quality Assurance whilst complying with legal requirements. In addition, as a non- EU country, Macedonia is not currently a member of any European or regional quality assurance body (ex. ENQA or CEENQA).

With regard to this, as Henshaw (2015) points out in her review of the development and impact of the QA in Macedonia, at a national level, there is a difference between the positive rhetoric and the level of improvement needed as well as a lack of actual realization of planned improvements. This research also highlights some issues such as the high standards not being realistic, poor interpretation and/or implementation, a lack of broader involvement of both public and private institutions and sometimes, international good practice not being shared widely enough between higher education stakeholders.

\section{Institutional context}

In a national context where the main focus is rigid compliance with very specific legal requirements, sometimes helpful and sometimes not, backed by inspections with the potential for heavy fines, institutions may rely more directly on international QA standards and guidelines for institutional development.

SEEU is a relatively young private-public, not-for-profit University that was established in 2001 within cooperation by two foundations (an international one, based in Switzerland and a national one, based in Tetovo, Macedonia). By 2003, the University started to make its own profit and at present it is $90 \%$ funded by student fees. Figure 1 below illustrates the University income in the academic year 2015/2016. 


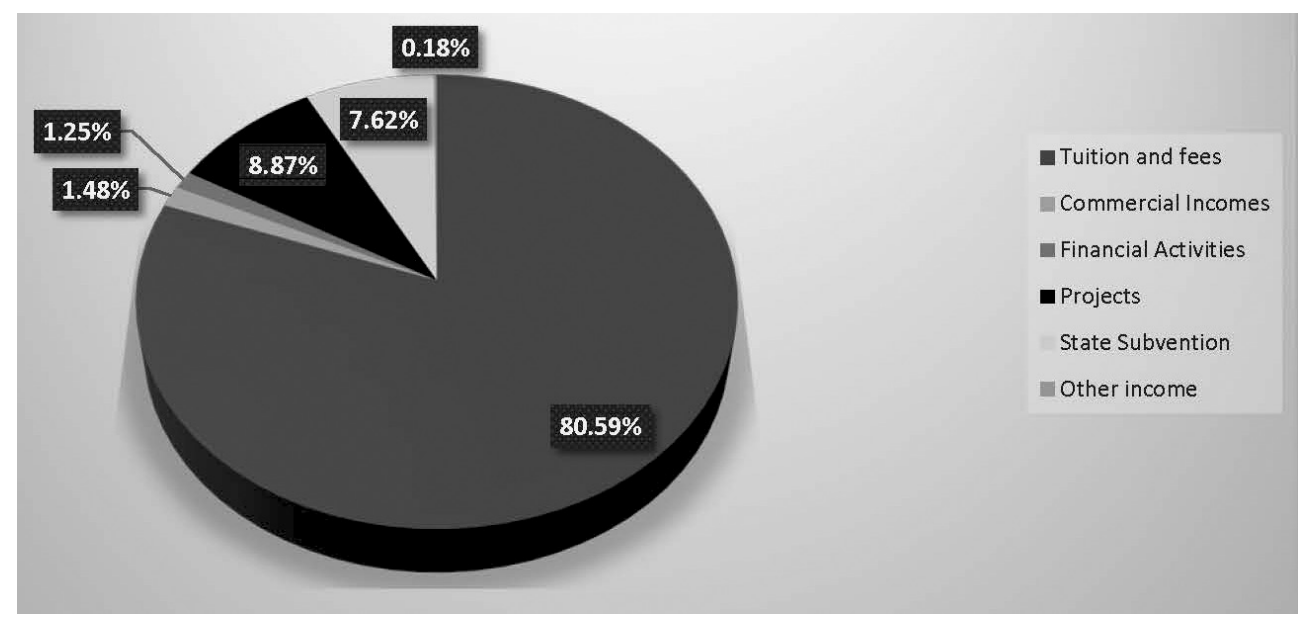

Figure 1. SEEU income breakdown, academic year2015/2016

This means that every aspect of QA is heavily student related. Yet, being in somewhat of a QA 'vacuum' nationally, the University has been able to look at broader trends and good practice and focus on the development of QA policy, internal procedures and development of a culture of collegial working based on external models, carefully adapted, operated and reviewed. It has focused on developing strategic policies, methods of institutional and programme review, active internal procedures such as for enhancing learning and teaching, including and considering students and their feedback, staff performance, as well as development of support services and information and information systems. It has thus managed to create a well -functioning QA system that is unique in the country and that distinguishes it from all other institutions wholly funded by student fees.

This analysis concentrates on three examples from the areas of QA review (institutional and at Faculties), student evaluation and learning and teaching which are key areas in the ENQA Standards and Guidelines and areas of current work.

\section{QA Review - institutional and Faculty based}

Concerning strategic policy and methods of institutional and program review, the University has a Quality Policy and has introduced a quality structure and methods of external review which actively add insight into strategic and operational planning and improvement. This means that we are in the same category as $63 \%$ of universities which have an institutional QA policy and an integrated approach to QA at institutional level (Trends 2015). The 
University's Quality Office leads and coordinates on various initiatives and processes, with a central Quality Assurance Management Commission and the Rector having oversight. Moreover,each academic unit has a Quality Team comprising staff, students and external stakeholders. These teams also function in line with a recent legal requirement for every academic unit to have a body for 'transparency and trust' (objectives unspecified except for looking at accreditation). They are now beginning to function more in line with their role of analyzing data and providing recommendations and advice to the Dean's Office and Faculty Councils.

The institution has also received valuable input from EUA external and follow-on evaluations and faculties have benefitted from two rounds of external program reviews from teams including international experts (not available nationally). In addition, the University receives annual visits from two international 'Quality Champions', identified by university management and the University Board, who provide a detailed report on agreed quality foci, for consideration at every level of the university. All these inputs have proved very valuable tools in creating change.

\section{Student evaluation and feedback}

In liaison with students and graduates, the University has developed a range of mechanisms for gauging student opinion, and using the feedback to enhance provision. As required by the Law and University Statute, there is actively encouraged student representation on all university bodies and review processes. There is the annual student survey led by the Quality Office and administrative staff in order to ensure objectivity. Results are sent to every professor who should include them in their annual appraisal; to the Faculty/Centre for consideration of more general issues as part of their annual Action Plan; and for use at University level for analysis and action as part of the annual Institutional Self Evaluation Report. The Student Parliament and Association is also given summary results.

The institution has taken steps to include a range of feedback methods which are integrated together for performance management. For example, it has also piloted an additional course based evaluation method, conducted in the Faculty of Business and Economics, and based on the TAP model, presented at the European Quality Assurance Forum, 2014, hosted by University of Barcelona. For this, a small team of experienced facilitators solicited oral and written feedback from every student group concerning helpful and unhelpful aspects of their learning, assessment practice, and other general comments. 
This resulted in every professor getting immediate, specific but unattributed written feedback from their class. There was also a summary provided to the Faculty management for consideration. This was very well received by students and staff and will be extended. Its impact has yet to be assessed but the Faculty is being encouraged to incorporate key findings in curricula revision and extension of practice such as links and visits with industry.

In addition, the University conducts other surveys aimed at getting different views. For example, in January, 2015, it conducted a survey with staff and students separately concerning staff compliance with the University Communication Standard. The Quality Office operated the survey amongst staff, the Ombudsperson amongst students, electronically. This revealed some very interesting results, such as students felt that generally academic staff were responsive and helpful but less effective when responding to complaints. The results were circulated for consideration by all stakeholders and may result in revised procedures for appeal and complaint. The university continues to be challenged by staffing capacities and skills to conduct such processes effectively and to get all levels of faculty and administration to actively respond to the results.

\section{Learning and Teaching}

The above-mentioned surveys provide valuable data for consideration and response and may result in enhancing teaching, learning and support with improved awareness, student satisfaction and achievement. However, as noted in the Trends 2015 report, "...There is an over-reliance on the student questionnaire as the sole method for evaluating teaching performance, instead of combining this with other instruments" (p. 93). It is also confirmed that learning and teaching continue to be the main focus of EHEA and one of the basic roles of the higher education institutions (Yerevan Communiqué, Zakon za visoko obrazovaniena RM, article 3 ).

With these broader imperatives in mind, and in the absence of concrete guidance from national bodies, the University has developed its own processes for evaluating and supporting the development of good learning and teaching practice. For example, an important internal process is the Procedure for the Observation of Learning and Teaching, which has been in place for seven years. This has involved both scheduled observations, with pre-observation and feedback meetings and reports highlighting effective methodologies and areas for improvement. The general judgments in the reports enable faculties and the university to analyze general data and to target 
training sessions as needed. Unannounced observations are also operated by Deans. The procedure has served a number of valuable purposes: it has increased awareness amongst staff of a range of pedagogical methodologies and approaches, provided opportunity for discussion on learning and teaching amongst academic staff, given the Faculties and University a sense of how learning was being delivered and showed students that we took their learning seriously. It has helped in the identification of training sessions, and provided concrete evidence for staffin the process of promotion. A number of surveys done by the Quality Office and individual staff concerning the process indicate that whilst there are operational issues and differences of opinion about relative value, there is a broad consensus that the process has had a positive effect (Emini 2015, Zeqiri, 2015).

Another related opportunity offered by the university is the provision of professional development for staff new to teaching. This consists of a teaching course, observation and the opportunity to engage in the scholarship of learning and teaching. This scheme has received very positive reviews from the newly appointed staff, who feel more confident in introducing student centered learning methods from the start of their careers.

A final example of institutional response is the current initiative on improving the assessment of students. Through discussion and training over a period of time, this has enabled the University to start on the development of faculty exam archives, peer monitoring and good practice pilots. The University has in this respect sought to include students in understanding more about their own learning, such as through student induction and including them in conferences (papers, posters, reporters).

\section{Conclusions}

The impact of external and national trends and guidance on the institutional practice and quality enhancement of SEEU is experienced very specifically by this institution but highlights some general dilemmas. At national level, the restrictive legislation and paper-only adherence to Bologna standards and guidelines coupled with the absence of any cohesive quality evaluation, benchmarking or other initiatives has not broadly supported improvement, merely compliance. It has also created a tension in the University between quality enhancement and quality control, such as in the area of staff performance. It has also meant that resources are targeted at meeting legal requirements and avoiding fines. 
The Bologna principles and other good practice guidance and reports have been much more positive for developing effective institutional mechanisms. These have given the University the autonomy to consider current trends and adapt them to institutional need with the aim of developing these further. On the other hand, the University has sometimes adopted international trends rather inflexibly, such as 3 year degrees for all programmes, regardless of professional standards and then created rather ad hoc solutions (ex. 3+ 1 for undergraduate degrees in law). Also, combining quality enhancement and quality assurance approaches, such as the use of teaching observation data both for appraisal and promotion and individual support, have created tensions which are complex. Finally, because the country or institution are not yet formally part of important European and regional QA European bodies, we sometimes miss out on access to events, training and partnerships which might be very useful.

The evaluation of the examples above indicates that institutionally, key QA processes have been developed in a transparent way, through consultations and are integrated and reviewed regularly. Indeed, the University has developed some of its own ideas (such as the use of Quality Champions) which have proved successful. The approach is still broadly evidence-based quality enhancement with follow on action. There is a focus on shared training and on regularly estimating value and usefulness.

It is obvious that not everything can be achieved within capacity and resource constraints and there is therefore a need to combine ideal and pragmatic solutions and multiple internal and external considerations. However, from all the considerations, it is evident that RM has no functioning QA evaluation system, while SEEU has managed to establish a quite well structured and functioning one. Yet, the three sides of the triangle, international, national and institutional, should complement and support each other, each having a different but positive input.

\section{References}

- Yerevan Communiqué, EHEA Ministerial Conference, 2015. Retrieved on 03.07.2015 from http://www.ehea.info/Uploads/SubmitedFiles/5 2015/112705.pdf

- Emini, R. (2015). Improving the Quality of Teaching and Learning through an Observation Process. Quality of Assessment, Qualification and Evaluation in Higher Education. Conference Proceedings. South East European University, 2015. ISBN 978-608-4503-99-6

- Henshaw. H. (2015). The development and Impact of Quality Assurance 
in the Republic of Macedonia. Quality of assessment, Qualification and Evaluation in Higher Education. Conference Proceedings. South East European University, 2015. ISBN 978-608-4503-99-6

- Loukkola, T., Morais, R.(2015). EUA Case Studies 2015.Members' Participation in U-Multirank: Experiences from the First Round'. Retrieved on 10.07. 2015 fromhttp://www.eua.be/Libraries/Publications homepage list/EUA_UMR_Publication_web.sflb.ashx

- Sursock, A.European University Association. Trends 2015: Learning and Teaching in European Universities. Retrieved on 6.07.2015 from: http:// eua.be/Libraries/Publications homepage list/EUA_Trends_2015 web. sflb.ashx

- The European Higher Education Area. The Bologna declaration of 19 June 1999. Retrieved on 09.07.2015 from http://www.magna-charta.org/ resources/files/BOLOGNA DECLARATION.pdf

- Zakonzavisokoobrazovanie (2008). Sluzbenvesnikna R. Makedonija br. 35 od 14.03.2008. Retrieved from: www. pravo.org.mk on 15.06.2015

- Standards and Guidelines for Quality Assurance in the European Higher Education AreaEuropean Association for Quality Assurance in Higher Education, 2009, Helsinki, 3rd edition Retrieved on 14.07.2015 from http:// www.enqa.eu/wp-content/uploads/2013/06/ESG_3edition-2.pdf

- Zeqiri, L. (2015). The Importance of Constructive and Applicable Pre and Post Teaching Observation Feedback. Quality of Assessment, Qualification and Evaluation in Higher Education. Conference Proceedings. South East European University, 2015. ISBN 978-608-4503-99-6. 